anales de psicología / annals of psychology

2020, vol. 36, nº 1 (january), 74-83

https://doi.org/10.6018/analesps.336311
(C) Copyright 2020: Editum. Servicio de Publicaciones de la Universidad de Murcia. Murcia (Spain) ISSN print edition: 0212-9728. ISSN on line edition (http://revistas.um.es/analesps): 1695-2294.

On line edition License Creative Commons 4.0: BY-NC-ND

\title{
Psychometric validation of the Environmental Reward Observation Scale (EROS) in breast cancer survivors
}

\author{
Concepción Fernández-Rodríguez*, Sonia González-Fernández, and Ignacio Pedrosa
}

University of Oviedo, Dept. of Psychology. Oviedo (Spain)

\begin{abstract}
Título: Validación psicométrica de la Environmental Reward Observation Scale (EROS) en supervivientes de cáncer de mama

Resumen: La pérdida de gratificaciones, como resultado de la enfermedad y tratamiento oncológico, se relaciona con problemas emocionales en supervivientes. Environmental Reward Observation Scale (EROS) es una escala para evaluar reforzamiento ambiental, desarrollada a partir de modelos conductuales que muestran la relación entre reforzamiento ambiental y estado emocional. Este estudio valida esta escala con supervivientes de cáncer de mama y analiza su utilidad para discriminar entre supervivientes con y sin trastornos emocionales. Un total de 219 mujeres supervivientes $\left(M_{\text {edad }}=52.97 ; D T_{\text {edad }}=7.50\right)$ completaron medidas de reforzamiento ambiental, activación y evitación conductual, y estado emocional. Los datos se ajustan a una estructura esencialmente unidimensional, mostrando una consistencia interna elevada y de moderadas a altas con todas las medidas empleadas. Fueron estadísticamente significativas las diferencias en las puntuaciones entre participantes con y sin trastorno emocional. Mediante curvas ROC se estableció el punto de corte óptimo para discriminar ansiedad y depresión. Aplicando la Teoría de Respuesta al Ítem, se encontró que todos los ítems muestran un poder de discriminación de moderado a alto para evaluar reforzamiento ambiental. La EROS se presenta como una medida fiable y válida que puede emplearse para mejorar la evaluación del estado emocional de supervivientes oncológicos.

Palabras clave: Supervivientes, Cáncer, Environmental Reward Observation Scale (EROS); Depresión, Ansiedad.
\end{abstract}

\section{Introduction}

Most cancer survivors adjust well to life after cancer but some experience emotional disorders. Anxiety and depression are the most frequent problems, with a prevalence superior to that found in healthy control groups ( $\mathrm{Yi} \&$ Syrjala, 2017). It is common for cancer survivors, having completed oncological treatment, to suffer from physical complaints, tiredness and a reduction in attention span and ability to concentrate. These or other physical repercussions frequently lead to patients reducing their involvement in relevant roles and/or pleasant activities (Cataldo \& Brodsky, 2013; Fernández, Padierna et al., 2011). Moreover, when faced with the oncological process and fear of cancer recurrence, survivors frequently experience unpleasant thoughts, feelings and memories (McGinty, Small, Laronga, \& Jacobsen, 2016). A common reaction to these experiences, encouraged and reinforced by the cultural context, is to try to avoid them. These attempts not only do not achieve the desired relief but generate more discomfort, contribute to perpetuating it, and limit involvement in important areas of life (Bardeen, 2015). Distancing oneself from day-to-day

* Correspondence address [Dirección para correspondencia]:

Concepción Fernández-Rodríguez, Department of Psychology, University of Oviedo. Plaza Feijoo, 33003 Oviedo (Spain).

E-mail: frconcha@uniovi.es

(Article received: 3-7-2018; revised: 9-10-2018; accepted: 21-12-2018)

\begin{abstract}
The loss of rewards resulting from oncological disease has been associated with emotional problems in cancer survivors. The Environmental Reward Observation Scale (EROS) evaluates environmental reinforcement and is based on behavioral models which show the relationship between environmental reinforcement and emotional state. The aim of this study is to analyze the psychometrical properties of this scale in breast cancer survivors and its usefulness in discriminating between survivors with and without emotional disorders. A total of 219 women survivors $\left(M_{a g e}=52.97 ; S D_{a g}=7.50\right)$ completed measures of environmental reinforcement, behavioral activation and avoidance, and emotional state. Data fit an essentially unidimensional structure, showing high internal consistency and correlations, varying from moderate to high, with all the measures used. In the EROS scores, statistically significant differences were found between participants with and without emotional disorders. Optimum cut-off point to discriminate between anxiety and depression was established via Receiver Operating Characteristic curve. Using the framework of the Item Response Theory model, all the items were found to have a power of discrimination for measuring environmental reinforcement ranging from moderate to high. The EROS is a psychometrically sound instrument, which can be used to improve assessment of emotional state in breast cancer survivors.

Keywords: Cancer survivors; Environmental Reward Observation Scale (EROS); Depression; Anxiety.
\end{abstract}

activities reduces the chances of maintaining contact with the rewarding situations and valuable conditions of life. This situation may be at the root of their emotional problems (González-Fernández et al., 2017).

The behavioral theories of depression posit that decrease in access to environmental rewards and/or the reinforcement of depressive behaviors and the punishment of healthy ones are causal factors predicting the beginning and the maintenance of clinical depression (Lewinsohn, 1974). The relationship between response-contingent positive reinforcement (RCPR) and emotional distress has been established (Cuijpers, van Straten, \& Warmerdam, 2007; Manos, Kanfer, \& Bush, 2010); in particular, a low level of RCPR is one of the critical predictors of clinical depression. Lewinsohn, Sullivan and Grosscup (1980) explain the decrease in RCPR as a consequence of the combination of the following conditions: a decrease in the number of reinforcement events; a decrease in the availability of these reinforcers in the environment; the absence of appropriate instrumental behaviors to experience gratifying contingencies; and an increase in exposure to aversive environmental experiences. For many cancer survivors, these four conditions are assimilated in their own experience of the oncological process. In line with this model, behavioral treatments for depression have been developed to facilitate increased access to reward while decreasing the intensity and frequency of punishing events 
(Lewinsohn, 1974). Currently, Behavioral Activation (BA) is a behavioral intervention for depression that shows promise in effectively treating depression by increasing goal and value-based activity levels, thereby eliciting increased response-contingent reinforcement (Lejuez, Hopko, Acierno, Daughters, \& Pagoto, 2011; Martell, Adis, \& Jacobson, 2001). The use of BA in treating emotional problems in cancer patients has also been supported by controlled studies (Fernández, Villoria, Fernández, González, \& Pérez, 2017; Hopko et al., 2013; 2008; 2003).

In order to assess the relationship between RCPR and emotional state, it is vital to carry out an objective and valid evaluation of the former. During the therapy, observation and behavior reports (e.g. daily diaries, activity schedules, home observations) represent invaluable strategies with regard to programming activities aimed at recovering reinforcement (Hopko \& Mullane, 2008). However, it is not easy to measure RCPR directly as this involves observation of relevant behaviors in the person's day-to-day environment over extended periods of time (Manos et al., 2010). Those researchers who have developed measures of RCPR have focused on measuring environmental rewards and exposure to pleasurable events. With the same objective in mind, Armento and Hopko (2007) developed the Environmental Reward Observation Scale (EROS). This scale is intended to be a proxy measure of RCPR by assessing the subjective experience of reinforcement. Items were designed to evaluate RCPR according to the formulation of Lewinsohn (1974). In its original version, with a sample of American students, the scale showed a unidimensional structure. Compared to commonly used depression and anxiety measures, as Beck Depression Inventory (BDI-II; Beck, Steer, \& Brown, 1996), The Center for Epidemiologic Studies Depression Scale (CESD; Radloff, 1977), or The State-Trait Anxiety Inventory (STAI; Spielberger et al., 1983), correlations with the EROS ranged between medium and large. In other validation studies which included the general population and also populations with emotional disorders, carried out with participants who were Spanish (Barraca \& Pérez-Álvarez, 2010), Colombian (Valderrama-Díaz, Bianchi-Salguero, \& Villalba-Garzón, 2016), or French-speaking Belgians (Wagener \& Blairy, 2015), in all cases there were found to be appropriate levels of internal consistency and also consistent validity evidence of internal structure. These findings indicate that the EROS could be a valid tool of environmental reinforcement, is congruent with the behavioral theories of depression and can facilitate the implementation and measuring of BA interventions. Indeed, the EROS has been used both to measure the notion of environmental reinforcement (Becoña et al., 2017; MacPherson et al., 2010), and to evaluate the effect of behavioral treatment of emotional disorders in subjects with health problems (Bombardier et al., 2017). In oncological populations, the EROS has been used when carrying out behavioral interventions and as a measure of the efficacy of Behavioral Activation in the treatment of emotional disorders (González-Fernández, Fernández-Rodríguez, PazCaballero \& Pérez-Álvarez, 2018; Lejuez et al., 2011, 2001). Despite this, and despite its evident usefulness, the EROS has not, however, been validated with this population.

Given this fact, the aim of this study is to obtain data regarding the reliability and validity evidence of the Spanish version of the EROS in a representative and relatively numerous sample of breast cancer survivors. At the same time, given the aforementioned peculiarities of populations of cancer survivors, the study also aims to analyze the sensitivity, specificity and ability of this scale to discriminate between survivors with and without depressive disorders.

\section{Method}

\section{Participants}

The participants recruited as cancer survivors attended the Oncology Department of the San Agustin Hospital (Avilés, Spain) or the Radiotherapy Department of the Central University Hospital of Asturias (Oviedo, Spain) for a scheduled medical review. The following inclusion criteria were established: breast cancer survivors, aged between 18 and 70 years, whose clinical situation was that of an oncological disease-free stage, confirmed by up-to-date medical report. The exclusion criterion was physical and/or cognitive deterioration which might hinder understanding and completing of measuring instruments.

The sample was made up of 219 women, aged between 31 and 67 years of age $(M=52.97 ; S D=7.50)$. Regarding marital status, $72.6 \%$ were married/living with their partner, $24.7 \%$ single/divorced and $2.6 \%$ widows. Only $9.3 \%$ lived alone and the rest lived with relatives. All the participants had undergone surgery, $82.5 \%$ had received hormonal treatment, $80 \%$ had received radiotherapy and 57.2\% chemotherapy. The time elapsed since the end of treatment ranged from 1 month to 8 years.

\section{Instruments}

Environmental Reward Observation Scale (EROS; Armento \& Hopko, 2007). The EROS is a 10-item self-administered questionnaire answered using a 4-option Likert, where 1 implies totally disagree and 4 means totally agree. which supplies information regarding the quantity and availability of reinforcement received from the patient's environment. It was designed to evaluate the RCPR according to the formulation of Lewinsohn (1974). The items evaluate both the number of events that are potentially reinforcing and the availability of reinforcement in the environment (e.g., "A lot of activities in my life are pleasurable", "Activities that used to be pleasurable are no longer gratifying", "My life is boring"), and the competence of the subject to obtain reinforcement from the environment (e.g., "It is easy for me to find enjoyment in my life", "I am satisfied with my accomplishments", "The activities I engage in usually have positive consequences"). In its original version (Ar- 
mento \& Hopko, 2007), it showed a unidimensional structure with adequate internal consistency $(\alpha=.85)$ and correlations, from moderate to strong, with different depression and anxiety scales (BDI-II $=-.78$; CESD $=-.79$; STAI-T $=-.71$; STAI-S $=-.80)$. Here, the Spanish version of the EROS was used (Barraca \& Pérez-Álvarez, 2010), for which data is available confirming its adequate reliability ( $a=$ .86) and validity evidence in relation to other variables (significant correlations with the BDI-II $=-.73$; STAI-S $=-.80$; STAI-T $=-.70$; BADS-T $=.69)$ and power to discriminate between clinical and non-clinical population.

Behavioral Activation for Depression Scale (BADS; Kanter, Mulick, Busch, Berlin, \& Martell, 2007). Consists of 25 items measuring four dimensions: Activation, Avoidance / Rumination, Work/School Impairment and Social Impairment. The emphasis is placed on behaviours that are directed toward the accomplishment of goals that the individual has determined to be important in each area. The scale provides scores for each of the dimensions and also a total score. High scores in Activation and in the total score show a higher level of activation, whilst higher scores in the other dimensions indicate greater avoidance patterns. The total score demonstrated acceptable internal consistency $(a=.79)$. The internal consistency for each subscale was also acceptable. Initial validity evidence of internal structure was established through significant correlations in the expected directions with different depression, anxiety and behavioral activation scales. The Spanish adaptation of the BADS (Barraca, Pérez-Álvarez, \& Lozano-Bleda, 2011) proved to be valid (significant correlations with the BDI-II = - .63; STAI$\mathrm{S}=-.68$; STAI-T $=-.70$; EROS $=.69)$ and had adequate internal consistency (between $a=.76$ and $a=.90$ ). Factor analysis confirmed the four-dimensional structure of the original instrument.

Acceptance and Action Questionnaire - II (AAQ-II; Bond et al., 2011). This is a 7-item, self-rating questionnaire designed to measure experiential avoidance and psychological inflexibility. The items reflect an unwillingness to experience unwanted emotions and thoughts and the inability to be in the present moment and behave towards values-directed actions when experiencing psychological events that could undermine them. High scores indicate a greater degree of experiential avoidance and psychological inflexibility. The AAQ-II showed adequate internal consistency $(\alpha=.84)$, and also demonstrates appropriate discriminant validity (correlations ranged between .60 and .82 with different depression, anxiety and behavioral activation scales). The Spanish translation of this questionnaire showed adequate internal consistency $(a=.88)$ and scores showed significant correlations with general scales measuring psychopathological state and quality of life (Ruiz, LangerHerrera, Luciano, Cangas, \& Beltrán, 2013).

Hospital Anxiety and Depression Scale (HADS; Zigmond \& Snaith, 1983) is a 14-item scale with 2 subscales, Anxiety (HADS-A) and Depression (HADS-D). In the depression and anxiety subscales, scores of 8-10 indicate probable cases and scores over 10 indicate clinical cases. For anxiety (HADS-A) this gave a specificity of .78 and a sensitivity of .90. For depression (HADS-D) this gave a specificity of .79 and a sensitivity of .83. Compared to commonly used depression and anxiety measures (BDI-II, CESD, STAI-T) correlations with the HADS-D and HADS-A ranged between .60 and .80 (Smarr \& Keefer, 2011). In psychooncology, the HADS score has been proven to be an accurate instrument in identifying cancer patients with depression and anxiety (Walker et al., 2007).

18-item Brief Symptom Inventory (BSI-18; Derogatis, 2001) was specifically developed as a highly sensitive and efficient screen for psychological distress. Consists of 18 items. Responses to the items allow scores to be obtained in 3 dimensions (Somatization, Depression and Anxiety) and a Global Severity Index (GSI), which resumes the general level of psychological distress. The inventory presents satisfactory reliability indexes (specifically Cronbach's a), both for the dimensions (ranging from .74 to .84) and for the General Distress Index (.89). A T score $\geq 63$ in the GSI or in two of the dimensions indicates a clinical case. Several studies show adequate reliability and validity of the inventory and endorse its use with Spanish samples (Galdón et al., 2008).

Short form of the 1978 Beck Depression Inventory (BDI-LA) based on the cognitive-affective subscale (BDI-IA-SCA; Beck \& Steer, 1993). Consists of the first thirteen items of the BDI-IA, referring to affective-cognitive symptoms of depression. Beck and Steer (1993) recommended its use when evaluating depression in patients with medical conditions. This instrument showed an adequate degree of criterion-related validity when distinguishing between those hospitalized patients with medical conditions who were and were not suffering from depressive disorders. Sanz and García-Vera (2007) found alpha coefficients $>.70$ in three Spanish samples and an acceptable index of diagnostic precision (area under the ROC curve $=.81$ ).

\section{Procedure}

Over a 6-month period, a consecutive preselection of cancer survivors was made from patients with a scheduled hospital appointment. All those women who fulfilled the selection criteria were informed, verbally and in writing, of the objectives and procedures of the study and of the guarantees regarding confidentiality in the evaluation and treatment of data. They were then asked to give their written consent. Each participant filled in the evaluation tests individually. All the participants, in line with a written protocol, were given the same instructions. The evaluation room was suitable, in terms of facilities and privacy, to allow the tests to be carried out adequately. None of the participants received additional help to fill in the questionnaires. The tests took approximately $20-30 \mathrm{~min}$. The subjects received no remuneration for participating in the study. 


\section{Statistical and Psychometric Analysis}

Data quality was assessed in terms of mean with confidence interval, variance, percentage of missing data, and extent of ceiling and floor effects. Floor and ceiling effects between $1 \%$ and $15 \%$ were defined as optimal (McHorney \& Tarlov, 1995).

To analyze the internal structure of EROS, a Confirmatory Factor Analysis (CFA) was conducted because of previous dimensionality confirmed among several studies and the absence of cross-loading factors based on the hypothesis of unidimensionality (Lloret-Segura, FerreresTraver, Hernández-Baeza, \& Tomás-Marco, 2014). Given the difficulty in predicting all the empirical relationships that may exist between the items, the Modification Indices (or measurement errors) were taken into account in order to find the best fit of the data to the model. As the original EROS states, a one-dimensional structure was proposed (Armento \& Hopko, 2007). All variables were categorical. Therefore, Weighted Least Squares Means and Variance adjusted estimation (WLSMV) was used as the extraction method (Muthén \& Muthén, 2012). The evaluation of the goodness of fit of the data to the model was performed via the $\chi^{2}$ divided by degrees of freedom, Root Mean Squared Error of Approximation (RMSEA), and Comparative Fit Index (CFI). Acceptable fitting models are achieved when the coefficient $\chi^{2} /$ degrees of freedom is lower than 3 , RMSEA $\leq .06$, CFI $\geq .90$, and SRMR $\leq .08$ (Asparouhov $\&$ Muthén, 2009). In the present study, adequate model fit was assumed if at least two of these fit indices supported model fit (Mosewich, Hadd, Crocker, \& Zumbo, 2013). CFA was carried out using software Mplus 7.3 (Muthén \& Muthén, 2012).

Closeness to unidimensionality was assessed through Unidimensional Congruence (UniCo), Explained Common Variance (ECV), and Mean of Item Residual Absolute Loadings (MIREAL) based on Pearson product-moment correlation matrix (Ferrando \& Lorenzo-Seva, 2014). Attending to standards, UNICO's values larger than .95, ECV's values larger than .85 , and MIREAL's values lower than .30 suggest that data can be treated as essentially unidimensional (Lorenzo-Seva \& Ferrando, 2017). Additionally, a standardized solution is graphically represented. Cronbach's a coefficient was used to estimate the reliability of each subscale.

In the framework of Item Response Theory models (IRT), the Samejima's Graded Response Model (GRM) was used (Samejima, 1970). The slope (discrimination parameter, a) and threshold (difficulty parameter, b) were estimated.
According to Baker (2001), a values ranging between 0.010.24 are very low, $0.25-0.64$ are low, $0.65-1.34$ are moderate, 1.35-1.69 are high, and above 1.7 are very high. While $a-$ parameter shows discrimination power of the item, $b$ parameter represents, for a given level of the trait $(\theta)$, the probability of selecting a specific response category or higher. The difference between the values of these parameters $\left(b_{3}-b_{1}\right)$ can be interpreted as an indicator of the ease with which a person may change his or her response from one category to another. Furthermore, the Information Function (IF) was estimated, showing the measurement accuracy of the instrument across different levels of trait (i.e. reinforcement received from the patient's environment). When observing IF, the solid line represents the information provided by the instrument, while the dotted line represents the standard error on the measurement. To study the relationships between EROS and the other variables of the study, Pearson's correlation was carried out.

Fit of the data to the normal distribution was tested using the Kolmogorov-Smirnov-Lilliefors test. A study of differences was performed based on clinical-non clinical cutoff points on the HADS instrument. Owing to the violation of the assumption of normality, Mann-Whitney $U$ test was carried out $(\mathrm{CL}=95 \%)$, using Cliff's Delta as effect size because of non-normal distribution.

A Receiver Operating Characteristic (ROC) curve was plotted to analyze the ability of the test to correctly classify those with and without emotional distress. Area under the curve (AUC) was estimated to determine the overall performance of the instrument to discriminate between those subjects with and without distress, where an area of 1 represents a perfect test. Estimation of optimal cut-off points were based on the relative costs of false negative and false positive results (Halpern, Albert, Krieger, Metz, \& Maidment, 1996).

\section{Results}

\section{Data quality analysis}

Comparing all items means and standard deviations are like almost all the items except items 5 and 7. The item response was high with a small number of missing answers (1.4-1.8\%). Floor effect was small in almost all the items (range $2.3-14.4 \%$ in eight out of ten cases. Floor effects were found in the cited items 5 and 7) and all items had a ceiling effect larger than $15 \%$ (range 18.6-56.3\%), and all the response choices were used in all items. 
Table 1. Data quality analysis.

\begin{tabular}{cccccc} 
& Mean & Variance & Missing (\%) & Floor (\%) & Ceiling $(\%)$ \\
\hline Item 1 & $3.219(3.05-3.39)$ & 0.952 & 1.8 & 7.4 & 52.6 \\
Item 2 & $3.093(2.90-3.29)$ & 1.210 & 1.4 & 14.4 & 50.9 \\
Item 3 & $2.874(2.70-3.05)$ & 1.003 & 1.8 & 10.7 & 34.4 \\
Item 4 & $3.028(2.84-3.21)$ & 1.097 & 1.4 & 12.0 & 44.0 \\
Item 5 & $2.433(2.21-2.65)$ & 1.557 & 1.8 & 36.3 & 29.8 \\
Item 6 & $3.093(2.90-3.29)$ & 1.266 & 1.4 & 14.4 & 53.7 \\
Item 7 & $2.372(2.16-2.59)$ & 1.536 & 1.8 & 36.3 & 28.8 \\
Item 8 & $3.102(2.93-3.27)$ & 0.920 & 1.4 & 8.3 & 43.5 \\
Item 9 & $3.200(3.02-3.38)$ & 1.016 & 1.8 & 10.7 & 52.6 \\
Item 10 & $3.233(3.09-3.37)$ & 0.653 & 1.8 & 2.3 & 44.2 \\
\hline
\end{tabular}

Psychometric properties of the EROS

First of all, validity evidence based on internal structure was checked via CFA, showing the following indexes: $\chi^{2} / \mathrm{df}$ $=3.90 ; \mathrm{CFI}=.95 ; \mathrm{RMSEA}=.116[.096-.137$; CL $=90 \%]$; UniCo $=.896 ; \mathrm{ECV}=.819 ; \mathrm{MIREAL}=.270$. Additionally, factor loadings of each item, and measurement errors (represented by a double-headed arrow) are shown in Figure 1. This unidimensional solution shows a reliability coefficient of $a=.91$.

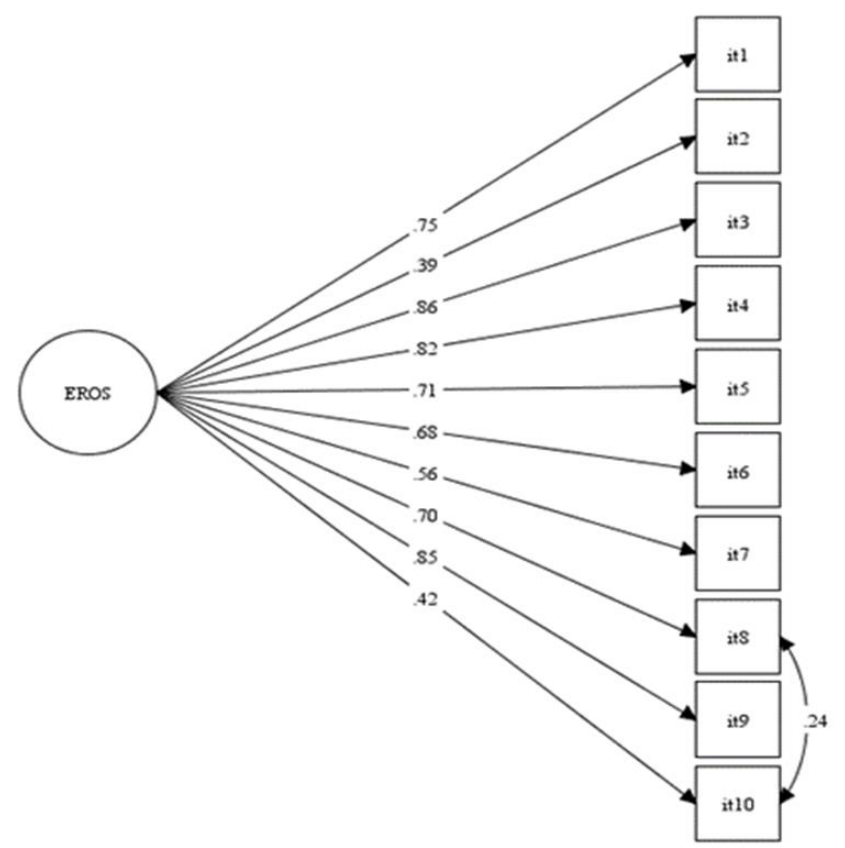

Figure 1. Standardized solution of unidimensional model of EROS.

\section{IRT Analysis}

Parameters $a$ and $b$ were estimated for the EROS instrument (Table 2). As can be seen, all items have a moderate to very high discrimination power (a-parameter). More specifically, half of the items exhibit a very high discrimination (values larger than 1.7). In relation to $b$ parameters, when using Samejima's GRM, the number of $b$ parameters derives from 1 minus the number of alternatives for that item. As there are four alternatives for the items in the EROS, there are three $b$-parameter values for each item. The largest differences $\left(b_{3}-b_{1}\right)$ in the EROS were found in items 10 and 2, and the smallest differences correspond to items 5, 9 and 6 .

Table 2. Item Response Theory (IRT) parameter estimates for Environmental Reward Observation Scale (EROS).

\begin{tabular}{cccccc}
\hline Items & $a$ & $b_{1}$ & $b_{2}$ & $b_{3}$ & $b_{3}-b_{1}$ \\
\hline 1 & 2.23 & -1.80 & -0.90 & -0.05 & 1.75 \\
2 & 0.72 & -2.79 & -1.71 & -0.15 & 2.64 \\
3 & 3.13 & -1.35 & -0.36 & 0.49 & 1.84 \\
4 & 2.71 & -1.36 & -0.57 & 0.21 & 1.57 \\
5 & 1.65 & -0.49 & 0.03 & 0.77 & 1.26 \\
6 & 1.59 & -1.51 & -0.74 & -0.12 & 1.39 \\
7 & 1.03 & -0.65 & 0.24 & 1.06 & 1.71 \\
8 & 1.97 & -1.78 & -0.79 & 0.25 & 2.03 \\
9 & 2.94 & -1.38 & -0.85 & -0.06 & 1.32 \\
10 & 0.95 & -4.26 & -1.81 & 0.35 & 4.61 \\
\hline
\end{tabular}

Regarding the measurement precision of the EROS, the IF exhibits maximum information between -1.5 and 0.5 trait levels, with the accuracy diminishing particularly in individuals with a latent trait level above +1 (Figure 2). 


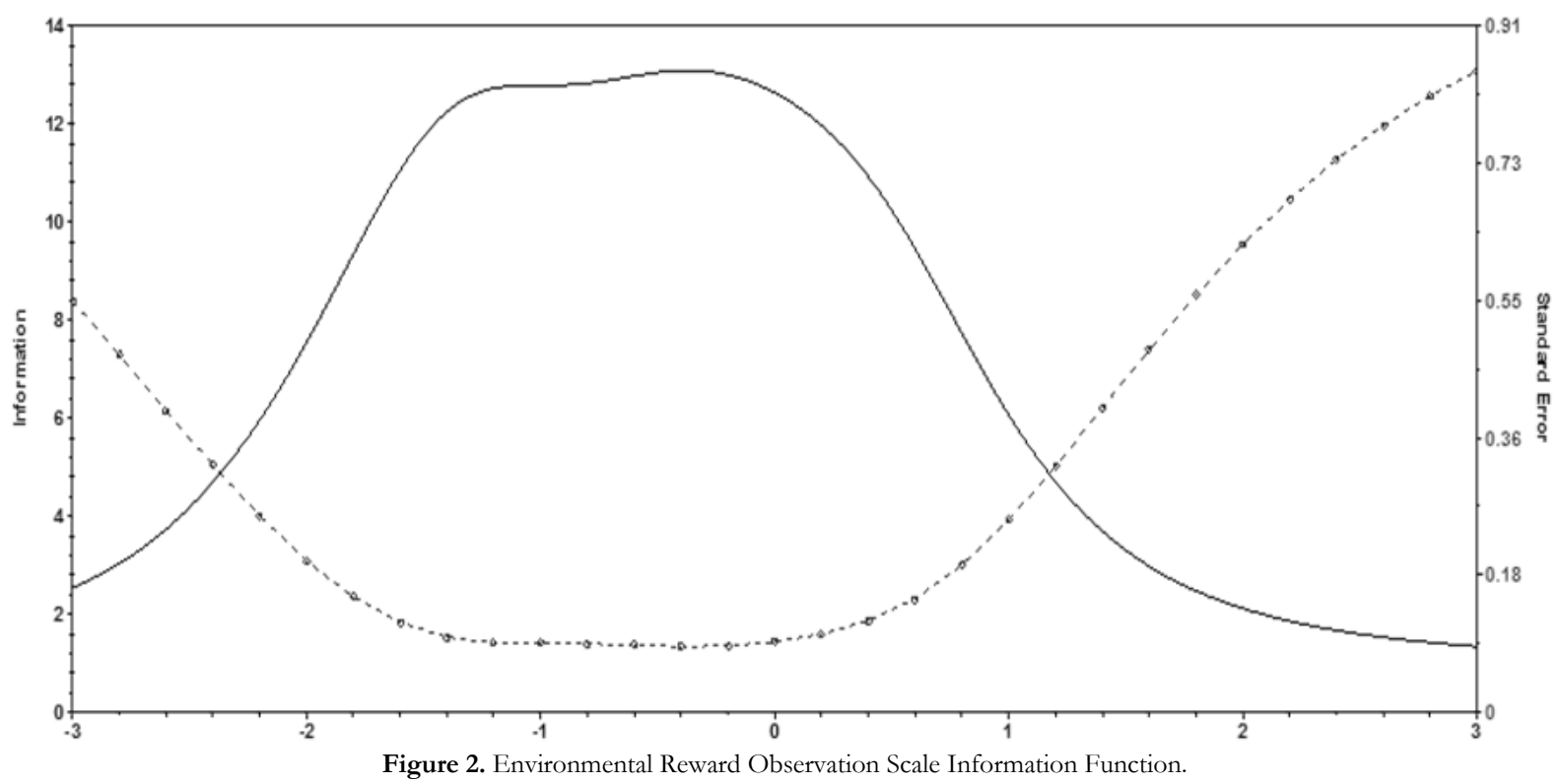

\section{$V$ alidity evidence in relation to other variables}

Table 3 shows the Pearson correlations between the EROS and the rest of the instruments described previously, considering their subscales in those cases in which the instruments are multidimensional. Medium to large correlations were found between the EROS and almost all the dimensions assessed in this sample.

Table 3. Pearson correlation coefficients between the Environmental Reward Observation Scale (EROS)and scales of anxiety, depression, general distress and psychological flexibility.

\begin{tabular}{|c|c|}
\hline & EROS \\
\hline AAQ-II & $-.723^{* *}$ \\
\hline BADS-Activation & $.436^{* *}$ \\
\hline BADS-Avoidance/Rumination & $-.539^{* *}$ \\
\hline BADS-Work/School Impairment & $-.570^{* *}$ \\
\hline BADS-Social Impairment & $-.588^{* *}$ \\
\hline BADS-Total & $.727^{* *}$ \\
\hline BDI-IA-SCA & $-.667^{* *}$ \\
\hline BSI-18-Somatization & $-.346^{* *}$ \\
\hline BSI-18-Depression & $-.631^{* *}$ \\
\hline BSI-18-Anxiety & $-.535^{* *}$ \\
\hline BSI-18- Global Severity Index & $-.581^{* *}$ \\
\hline HADS-Anxiety & $-.608^{* *}$ \\
\hline HADS-Depression & $-.727^{* *}$ \\
\hline HADS-Total & $-.724^{* *}$ \\
\hline
\end{tabular}

Note: $p<.001=(* *)$. AAQ-II: Acceptance and Action Questionnaire-II. BADS: Behavioral Activation for Depression Scale. BDI-IA-SCA: Short form of the 1978 Beck Depression Inventory (BDI-IA) based on the cognitive-affective subscale. BSI-18: Brief Symptom Inventory. HADS: Hospital Anxiety and Depression Scale.

\section{Study of differences based on clinical and non-clinical condition}

As assumption-of-normality-test was not confirmed $(p<$ .001), a Mann-Whitney $U$-test was carried out to analyze statistically significant differences in the EROS scores of the participants. Participants were split into two subsamples (clinical and non-clinical groups) based on the standard HADS cut-off point. On the basis of the HADS instrument, statistically significant differences were found between both groups in anxiety $(p<.001 ; \delta=0.66)$, depression $(p<.001 ; \delta$ $=0.92)$ and total HADS score $(p<.001 ; \delta=0.62)$. As can be seen, effect sizes were medium for anxiety and total HADS score, while this effect is especially large related to the depression subscale.

\section{Estimation of diagnostic-test sensitivity and specificity}

Clinical instruments require the establishment of a cutoff point from continuous data, which will give information about sensitivity and specificity of the instrument. To achieve this, ROC curve and AUC were carried out to analyze sensitivity, specificity and overall performance of the EROS, using the HADS as gold standard to define the dichotomous true clinical state. From the results obtained, the overall performance can be considered to range from good to very good: Anxiety $\left(\mathrm{AUC}_{\text {anxiety }}=.832\right.$ [.767-.897; CL $=95 \%])$, Depression $\left(\mathrm{AUC}_{\text {depression }}=.958[.930-.985 ; \mathrm{CL}=\right.$ $95 \%])$, and Total Score $\left(\mathrm{AUC}_{\text {total }}=.809[.743-.874 ; \mathrm{CL}=\right.$ $95 \%])$.

When estimating the optimal cut-off points of the EROS based on the gold standard established, the following results were found in terms of sensitivity and specificity of the instrument. For the HADS anxiety subscale, a score of 29 points can be defined as the optimal cut-off point, showing a sensitivity of $74.80 \%$ and specificity of $80.00 \%$. Regarding the HADS depression subscale, a score of 25 points can be defined as the optimal cut-off point, showing a sensitivity of $82.70 \%$ and specificity of $100.00 \%$. For the total HADS score, 33 points can be defined as the optimal cut-off point, showing a sensitivity of $70.60 \%$ and specificity of $81.70 \%$. 


\section{Discussion}

The emotional problems of cancer survivors have been related to a progressive loss of rewards resulting from adverse experiences in the oncological process. With this in mind, the aims of this study were, firstly, to determine whether the Environmental Reward Observation Scale is a valid and reliable instrument for evaluating the notion of environmental reinforcement in breast cancer survivors and, secondly, to examine the capacity of this scale to discriminate between survivors with and without depressive disorders.

With a clinically and socio-demographically representative sample of breast cancer survivors containing an adequate representation of participants with and without emotional disorders, the results obtained confirm the psychometric guarantees of the EROS in this population. Regarding evidence of construct validity, the confirmatory factor analysis indicates the unidimensionallity of the scale. This result coincides with those reported by Armento and Hopko (2007) and by other validation studies (Barraca \& Pérez-Álvarez, 2010; Valderrama-Díaz et al., 2016; Wagener \& Blairy, 2015). It should be noted that, in our study, most of the fit indexes were observed to be below the standard criterion, and only the MIREAL and CFI indexes can be considered appropriate. The literature in general recommends a flexible approach to evaluating overall model fit, using a global analysis rather than a strict reliance on arbitrary cut-off values that may not be relevant to the specific research context (West, Taylor, \& Wu, 2012). Consequently, in this case, considering fit indexes as a whole, the adequate factor loading shown by all items, the adequate reliability, which demonstrates a high relationship between all the items, and the fit indexes found in other papers, it seems plausible to define EROS as an essentially unidimensional instrument. It is, therefore, a test with sufficient psychometric guarantees, in the field of Psycho-oncology, for use in research into the relationships between the loss of response-contingent positive reinforcement and depression (Hopko et al., 2003; Lewinsohn, 1974; Martell, Addis, \& Jacobson, 2001).

With regard to the reliability of the test, it is to be underlined that this was greater than that found in the aforementioned previous validation studies. Not only was there found to be a high relationship between the individual items, but also, when analyzed within the Item Response Theory, all have a moderate to very high power of discrimination regarding the perception of available environmental reinforcement of breast cancer survivors. Those items which would allow a particularly precise differentiation between survivors with a greater or lesser subjective perception of environmental reinforcement are: "In general I am very satisfied with the way I spend my time (item 3)", "My life is boring (item 9)", "It is easy for me to find enjoyment in my life (item 4)", "A lot of activities in my life are pleasurable (item 1)". As might be expected, these items are the ones which have the highest factor loadings and item-test correlations $(>.80)$. It should be pointed out that, in line with Lewinsohn's formulation of RCPR (Lewinsohn, 1974), these items would be evaluating both the quantity and potential availability of environmental reward (items 9 and 1) and the competence of the person to obtain reinforcement from her environment (items 3 and 4). These results offer further evidence of the consistency of the concept of RCPR. Furthermore, in light of the relationship existing between emotional state and RCPR (Cuijpers, van Straten, \& Warmerdam, 2007; Manos et al., 2010), they would support the effectivity ofbehavioral interventions aimed at increasing reinforcement in order to reduce levels of emotional distress. With regard to future studies, the question arises as to whether evaluating only those items which have shown the greatest discriminatory capacity may be sufficient in order to make a precise estimation of the survivor's subjective perception of environmental reinforcement. If this were so, it would be possible to elaborate a briefer instrument and reduce evaluation time. The test would in turn be made simpler and more efficacious.

In the analysis of those items with the smallest $b_{3}-b_{1}$ difference values, it is also worth noting that the conditions which appear to be most susceptible to change are: "Other people seem to have more fulfilling lives (item 5)", "My life is boring (item 9)", "Activities that used to be pleasurable are no longer gratifying (item 6)". In contrast, those in which change appears less probable are: "Lately I have found that many experiences make me unhappy (item 2)", "The activities I engage in usually have positive consequences (item 10)", "I am satisfied with my accomplishments (item 8)". These results have clear clinical implications. It can be concluded that, when dealing with emotional disorders in breast cancer survivors, it would be more effective and efficacious to focus the first sessions of the intervention on that condition which can be more easily modified (according to items 5, 9 and 6), that is, on promoting an increase in rewarding activities which ensure the availability of environmental rewards. However, ultimately, the efficacy of the intervention depends on being able to modify also those conditions which are less probable to change (according to our results, items 2, 10, 8) as this would imply that subjects had acquired competences to ensure the contingent reinforcement of their actions. These findings are totally coherent with the principles and procedures of behavioral therapies of depression, and in particular of Behavioral Activation (Lejuez et al., 2001; Martell et al., 2001). From the very first sessions, this therapy establishes a program of rewarding activities which are consistent with the person's values with a view to facilitating an increase in RCPR. As in any contextual therapy, the ultimate aim is to provide the person with competences which enable him/her to identify and change those response patterns which lead to depression and/or anxiety. For that reason, special attention is paid to identifying and modifying strategies of behavioral avoidance. Avoidance patterns distance the person from those day-to-day situations on which his/her rewards depend and reduce the possibilities of 
undertaking other healthier strategies of interaction with the environment (Bardeen, 2015; Trindade, Ferreira \& PintoGouveia, 2017).

A similar interpretation can be made of the strong and negative correlation of this measure with measures of depression (HADS-D, BSI-D; BDI-IA-SCA), of behavioral avoidance (AAQ-II, BADS-A/R, BADS-WSI, BADS-SI) and of anxiety (HADS-A, BSI-A). There is an equally strong, but positive, correlation with measures of activation (BADST). These results coincide with those reported by other authors, who, with different clinical populations and general population, have identified a relationship between depression and RCPS (Folke \& Kanter, 2016; Hill, Buitron, \& Pettit, 2017), and between patterns of behavioral avoidance and emotional state (Brem, Shorey, Anderson, \& Stuart, 2017; González-Fernández et al., 2017). Both conditions, as pointed out previously, are principal objectives of behavioral therapies for depression. Consequently, we suggest that the EROS could also be a suitable instrument for evaluating the results of behavioral treatment of emotional disorders in breast cancer survivors. This belief is also supported by the results, which confirm that participants with and without emotional problems differ with regard to their levels of perceived environmental reward. Furthermore, as predicted by the model on which the scale is based, the particularly large effect size of the differences between the scores of survivors with and without depression are especially noteworthy.

In our study, the Information Function of the EROS indicates that it would be for those breast cancer survivors with a score around the mean of the population (approximately between 17 and 27) for whom the scale would best estimate perception of available environmental reinforcement. It is precisely within this range that the cutoff point for depression (25) is extremely sensitive and most specific. The use of the Hospital Anxiety and Depression Scale as a gold standard measure is endorsed by its properties and by its widespread application in evaluating emotional distress free from the bias of physical symptomatology. Walker et al. (2007) found somatic symptoms of depression to be confounding factors in patients with medical illnesses. The same could occur in cancer survivors. It is, nevertheless, true that some authors have questioned the suitability of this instrument for differentiating between depression and anxiety (Burns, Hofer, Curry, Sexton, \& Doyle, 2014). In light of the lack of other studies into this matter, one possible subject of future study could be the use of other measures and/or procedures of clinical diagnosis as gold standard comparison criteria for confirming the adjustment of cut-off points in the EROS.
The degree of similarity shown between the survivors' experiences during the oncological process would suggest that the results of this study could be extended to other cancer patient populations. However, the fact that this population is mainly female raises the question of whether the same observations could be applied to a population of male survivors. Although it appears unlikely that gender would affect the unidimensional structure of the scale, as has been shown in previous validation studies using samples with an adequate representation of both men and women, it could affect the scores. It is known that women suffer from and/or seek help for more emotional distress than men (Kuehner, 2017). In oncological survivors, gender has also been related to different levels of depression (Bevilacqua et al., 2018), emotional distress and fear of a relapse (KochGallenkamp et al., 2016). Furthermore, some studies suggest that women appear to be more sensitive to reinforcement and rewards (Ryba \& Hopko, 2012; Tull, Gratz, Latzman, Kimbrel, \& Lejuez, 2010). To sum up, due to the great clinical value that use of this scale appears to have with oncological patients, and also in order to gain more profound insights into the relationships between RCPR and emotional distress, it would be of interest to carry out further studies using adequately-balanced samples in terms of gender and at different stages of different types of cancer. In order to overcome some of the limitations of this study, it would be recommendable to use a longitudinal evaluation design to examine the guarantees offered by the instrument.

\section{Conclusion}

The EROS is shown to be a valid and reliable measure for the evaluation of environmental rewards in breast cancer survivors. Its use is recommended for estimating the degree of loss of contact with reinforcers of day-to-day life which patients undergo as a result of the oncological treatment and disease and which increase the probability of emotional disorders.

Funding: This research was supported by the Spanish National Plan for Scientific and Technical Research and Innovation, under contract PSI2014-55594-P, grants awarded to the first author.

Ethical Approval: The study was conducted in accordance with codes of ethics and conduct specified by the Research Ethics Committee of the Principality of Asturias, Spain (Ref.:45/14). Informed consent was obtained from all individual participants included in the study. All procedures performed in studies involving human participants were in accordance with the ethical standards of the institutional and/or national research committee and with the 1964 Helsinki declaration and its later amendments or comparable ethical standards. 


\section{References}

Armento, M.E., \& Hopko, D.R. (2007). The environmental reward observation scale (EROS), development, validity, and reliability. Behavior Therapy, 38, 107-119. doi: 10.1016/j.beth.2006.05.003.

Asparouhov, T., \& Muthén, B. (2009). Exploratory Structural Equation Modeling. Structural Equation Modeling: A Multidisciplinary Journal, 16, 397-438. doi:10.1080/10705510903008204

Barraca, J., Pérez-Álvarez, M., \& Lozano-Bleda, J. (2011). Avoidance and Activation as Keys to Depression: Adaptation of the Behavioral Activation for Depression Scale in a Spanish Sample. The Spanish Journal of Psychology, 14, 998-1009. Available in: http:/ / www.redalyc.org/articulo.oa?id=17220620045.

Barraca, J., \& Pérez-Álvarez, M. (2010). Spanish adaptation of the Environmental Reward Observation Scale (EROS). Ansiedad y Estrés, $16,95-107$.

Bardeen, J. R. (2015). Short-term pain for long-term gain: The role of experiential avoidance in the relation between anxiety sensitivity and emotional distress. Journal of Anxiety Disorders, 30, 113-119. doi: 10.1016/j.janxdis.2014.12.013

Baker, F. (2001). The basics of item response theory. College Park: ERIC Clearinghouse on Assessment and Evaluation, University of Maryland.

Beck, A.T., \& Steer, R.A., (1993). Beck Depression Inventory Manual. San Antonio, TX: The Psychological Corporation.

Beck, A. T., Steer, R. A., \& Brown, G. K. (1996). Beck Depression Inventory-II. San Antonio, TX: The Psychological Corporation.

Becoña, E., Martínez-Vispo, C., Senra, C., López-Durán, A., RodríguezCano, R., \& Fernández del Río, E. (2017). Cognitive-behavioral treatment with behavioral activation for smokers with depressive symptomatology: study protocol of a randomized controlled trial. $B M C$ Psychiatry, 17, 134. doi:10.1186/s12888-017-1301-7.

Bevilacqua, L.A., Dulak, D., Schofield, E., ... \& Alici, Y. (2018). Prevalence and Predictors of Depression, Pain, and Fatigue in Older- versus Younger-Adult Cancer Survivors. Psycho-Oncology. doi: 10.1002/pon.4605.

Bombardier, Ch., Fann, J., Ludman, E., Vannoy, S., Dyer, J., Barber, J., \& Temkin, N. (2017). The Relations of Cognitive, Behavioral, and Physical Activity Variables to Depression Severity in Traumatic Brain Injury: Reanalysis of Data from a Randomized Controlled Trial. The Journal of Head Trauma Rehabilitation, 32, 343-53 doi: 10.1097/HTR.0000000000000288.

Bond, F.W., Hayes, S.C., Baer, R.A., Carpenter, K.M., Guenole, N., Orcutt, H.K., \& Zettle, R.D. (2011). Preliminary psychometric properties of the Acceptance and Action Questionnaire - II: a revised measure of psychological inflexibility and experiential avoidance. Behavior Therapy, 42, 676-688. doi: 10.1016/j.beth.2011.03.007.

Brem, M.J., Shorey, R.C., Anderson, S., \& Stuart, G.L. (2017). Depression, anxiety, and compulsive sexual behaviour among men in residential treatment for substance use disorders: The role of experiential avoidance. Clinical Psychology and Psychotherapy, 24, 1246-1253. doi: 10.1002/cpp.2085.

Burns, A., Hofer, S., Curry, P., Sexton, E., \& Doyle F. (2014). Revisiting the dimensionality of the Hospital Anxiety and Depression Scale in an international sample of patients with ischemic heart disease. Journal of Psychosomatic Research, 77, 116-121. doi: 10.1016/j.jpsychores.2014.05.005.

Cataldo, J., \& Brodsky, J.L. (2013). Lung cancer stigma, anxiety, depression and symptom severity. Oncology, 85, 33-40. doi:10.1159/000350834.

Cuijpers, P., van Straten, A., \& Warmerdam, L. (2007). Behavioral activation treatments of depression: A meta-analysis. Clinical Psychology Review, 27, 318-326. doi: 10.1016/j.cpr.2006.11.001.

Derogatis, L.R. (2001). Brief Symptom Inventory (BSI)-18. Administration, Scoring and Procedures Manual. Minneapolis: NCS Pearson.

Fernández, C., Padierna, C., Villoria, E., Amigo, I., Fernández, R., \& Peláez, I. 2011. Impact of anxiety and depression on the physical status and daily of cancer patients during chemotherapy. Psicothema, 23, 374381. Retrieved

from http://www.psicothema.com/psicothema.asp?ID=3897.
Fernández, C., Villoria, E., Fernández, P., González, S., \& Pérez M. (2017). Effects of Behavioral Activation on the quality of life \& emotional state of lung cancer and breast cancer patients during chemotherapy treatment. Behavior Modification, 1-30 doi:10.1177/0145445517746915.

Ferrando, P. J., \& Lorenzo-Seva, U. (2014). El análisis factorial exploratorio de los ítems: algunas consideraciones adicionales. Anales de Psicología, 30(3), 1170-1175. doi: 10.6018/analesps.30.3.199991

Folke, F., \& Kanter, J. W. (2016). A learning theory account of depression. Personality and Social Psychology, 57, 3-82. doi: $10.1111 /$ sjop. 12233.

Galdón, M.J., Dura, E., Andreu, Y., Ferrando, M., Murgui, S., Pérez, S., \& Ibañez, E. (2008). Psychometric properties of the Brief Symptom Inventory-18 in a Spanish breast cancer sample. Journal of Psychosomatic Research, 65, 533-539. doi:10.1016/j.jpsychores.2008.05.009.

González-Fernández, S., Fernández-Rodríguez, C., Mota-Alonso, M.J. García-Teijido, P., Pedrosa, I., \& Pérez-Álvarez, M. (2017). Emotional state and psychological flexibility in breast cancer survivors. European Journal of Oncology Nursing, 30, 75-83. doi: 10.1016/j.ejon.2017.08.006.

González-Fernández, S., Fernández-Rodríguez, C., Paz-Caballero, D., \& Pérez-Álvarez. M. (2018). Treating anxiety and depression of cancer survivors: Behavioral activation versus acceptance and commitment therapy. Psicothema, 30, 14-20. doi: 10.7334/psicothema2017.396

Halpern, E., Albert, M., Krieger, A., Metz, Ch., \& Maidment, A. (1996). Comparison of receiver operating characteristic curves on the basis of optimal operating points. Academic Radiology, 3, 245-253.

Hill, R.M., Buitron, V., \& Pettit, J.W. (2017). Unpacking Response Contingent Positive Reinforcement: Reward Probability, but Not Environmental Suppressors, Prospectively Predicts Depressive Symptoms via Behavioral Activation. Journal of Psychopathology and Behavioral Assessment, 39, 498. doi:10.1007/s10862-017-9600-3.

Hopko, D.R., Funderburk, J.S., Shorey, R.C., McIndoo, C.C., Ryba, M.M., File, A.A., ... \& Vitulano, M. (2013). Behavioral Activation and Problem-Solving Therapy for Depressed Breast Cancer Patients: Preliminary Support for Decreased Suicidal Ideation. Behavior Modification, 37, 747-767. doi: 10.1177/0145445513501512.

Hopko, D. R., Lejuez, C. W., Ruggiero, K. J., \& Eifert, G. H. (2003) Contemporary behavioral activation treatments for depression: Procedures, principles, and progress. Clinical Psychology Review, 23, 699717. doi.10.1016/S0272-73580300070-9

Hopko, D.R., \& Mullane, C.M. (2008). Exploring the relation of depression and overt behavior with daily diaries. Behaviour Research and Therapy, 46, 1085-89. doi. 10.1016/j.brat.2008.05.002.

Kanter, J.W., Mulick, P.S., Busch, A.M., Berlin, K.S., \& Martell, C.R. (2007). The behavioral activation for depression scale (BADS): psychometric properties and factor structure. Journal of Psychopathology and Behavioral Assessment, 29, 191-202. doi:10.1007/s10862-006-9038-5.

Koch-Gallenkamp, L., Bertram, H., Eberle, A., Holleczek, B., SchmidHöpfner, S., Waldmann, A., . . \& A Arndt, V. (2016). Fear of recurrence in long-term cancer survivors. Do cancer type, sex, time since diagnosis, and social support matter? Health Psychology, 35(12), 13291333. doi: $10.1037 /$ hea0000374.

Kuehner, C. (2017). Why is depression more common among women than among men? The Lancet Psychiatry, 4(2), 146-158. doi. 10.1016/S2215 0366(16)30263-2.

Lejuez, C., Hopko, D., Acierno, R., Daughters, S., \& Pagoto, S. (2011). Ten Year Revision of the Brief Behavioral Activation Treatment for Depression (BATD): Revised Treatment Manual (BATD-R). Behavior Modification, 35, 111-161. doi: 10.1177/0145445510390929.

Lejuez, C., Hopko, D., \& Hopko, S. (2001). A Brief Behavioral Activation Treatment for Depression. Behavior Modification, 25, 255-286. doi: 10.1177/0145445501252005.

Lewinsohn, P. (1974). A behavioral approach to depression. In R. Friedman \& M. Katz (Eds.), The psychology of depression: Contemporary Theory and Research (pp. 157-178). Hoboken, USA: Wiley. 
Lewinsohn, P., Sullivan, J., \& Grosscup, S. (1980). Changing reinforcing events: An approach to the treatment of depression. Psychotherapy: Theory, Research and Practice, 17, 322-334. doi: 10.1037/h0085929.

Lloret-Segura, S., Ferreres-Traver, A., Hernández-Baeza, A., \& TomásMarco, I. (2014). Exploratory Item Factor Analysis: A practical guide revised and up-dated. Anales de Psicologial Annals of Psychology, 30(3), 1151-1169. doi: 10.6018/analesps.30.3.199361

Lorenzo-Seva, U., \& Ferrando, P.J. (2017). Factor. Manual of the Program. Tarragona: Universitat Rovira i Virgili.

McGinty, H. L., Small, B. J., Laronga, C., \& Jacobsen, P. B. (2016). Predictors and patterns of fear of cancer recurrence in breast cancer survivors. Health Psychology, 35, 1-9. doi: 10.1037/hea0000238.

MacPherson, L., Tull, M. T., Matusiewicz, A. K., Rodman, S., Strong, D. R., Kahler, C. W., ... \& Lejuez, C. W. (2010). Randomized controlled trial of behavioral activation smoking cessation treatment for smokers with elevated depressive symptoms. Journal of Consulting and Clinical Psychology, 78(1), 55-61. doi: 10.1037/a0017939.

Manos, R., Kanter, J., \& Busch, A. (2010). A critical review of assessment strategies to measure the behavioral activation model of depression. Clinical Psychology Review, 30, 547-561. doi: 10.1016/j.cpr.2010.03.008.

Martell, C., Addis, M., \& Jacobson, N. (2001). Depression in Context: Strategies for Guided Action. New York: W. W. Norton and Company, Inc.

McHorney, C.A., \& Tarlov, A.R. (1995). Individual-patient monitoring in clinical practice: are available health status surveys adequate? Qual Life Res., 4(4), 293-307

Mosewich, A. D., Hadd, V., Crocker, P. R. E., \& Zumbo, B. D. (2013). Invariance testing of the SF-36 health survey in women breast cancer survivors: Do personal and cancer-related variables influence the meaning of quality of life items? Social Indicators Research, 110, 559-557. doi:10.1007/s11205-011-9944-0.

Muthén, L.K., \& Muthén, B.O. (2012). Mplus User's Guide. Seventh Edition. Los Angeles, CA: Muthén and Muthén.

Radloff, L.S. (1997). The CES-D Scale: A Self-Report Depression Scale for Research in the General Population. Applied Psychological Measurement, 1 (3), 387-415.

Ryba, M., \& Hopko, D. (2012). Gender Differences in Depression: Assessing Mediational Effects of Overt Behaviors and Environmental Reward through Daily Diary Monitoring. Depression Research and Treatment, 865679. doi 10.1155/2012/865679.

Ruiz, F.J., Langer-Herrera, A.I., Luciano, C., Cangas, A.J., \& Beltrán, I. (2013). Measuring experiential avoidance and psychological inflexibility: The Spanish version of the Acceptance and Action Questionnaire - II. Psicothema, 25, 123-129. doi: 10.7334/psicothema2011.239
Samejima, F. (1970). Estimation of latent ability using a response pattern of graded scores. Psychometrika, 17, 1. doi:10.1007/BF03372160.

Sanz, J., \& García-Vera, M.P. (2007). A psychometric analysis of the short forms of the 1978 version of the Beck Depression Inventory. Psicologia Conductual, 15, 191-214.

Smarr, K. L., \& Keefer, A. L. (2011). Measures of depression and depressive symptoms: Beck Depression Inventory-II (BDI-II), Center for Epidemiologic Studies Depression Scale (CES-D), Geriatric Depression Scale (GDS), Hospital Anxiety and Depression Scale (HADS), and Patient Health Questionnaire-9 (PHQ-9). Arthritis Care ¿ Research, 63(S11), S454-S466. doi:10.1002/acr.20556

Spielberger, C. D. (1983). Manual for the State-Trait Anxiety Inventory (STAI). Palo Alto, CA: Consulting Psychologists Press.

Trindade, I., Ferreira, C., \& Pinto-Gouveia, J. (2017). Roles of body image-related experiential avoidance and uncommitted living in the link between body image and women's quality of life, Women and Health, 58 (1), 38-50, doi: 10.1080/03630242.2016.1267688

Tull, M., Gratz, K., Latzman, R., Kimbrel, N., \& Lejuez, C. (2010). Reinforcement sensitivity theory and emotion regulation difficulties: A multimodal investigation. Personality and Individual Difference, 49, 989994. doi: 10.1016/j.paid.2010.08.010.

Valderrama-Díaz, M. A., Bianchi-Salguero, J. M., \& Villalba-Garzón, A. A (2016). Validation of the Environmental Reward Observation Scale (EROS) in Colombian population. Universitas Psychologica, 15. doi: 10.11144/javeriana.upsy15-4.vero.

Wagener, A., \& Blairy, S. (2015). Validation and Psychometric Properties of the French Versions of the Environmental Reward Observation Scale and of the Reward Probability Index. Psychologica Belgica, 55, 71-86, doi: $10.5334 / \mathrm{pb} . \mathrm{bg}$.

Walker, J., Postma, K., McHugh, G.S., Rush, R., Coyle, B., Strong, V., \& Sharpe, M. (2007). Performance of the Hospital Anxiety and Depression Scale as a screening tool for major depressive disorder in cancer patients. Journal of Psychosomatic Research, 63, 83-91. doi: 10.1016/j.jpsychores.2007.01.009.

West, S.G., Taylor A.B., \& Wu W. (2012). Model fit and model selection in structural equation modelling. In Handbook of Structural Equation Modeling, Hoyle, R.H., (Ed.). New York, NY: Guilford. pp. 209-231.

Yi J.C., \& Syrjala K.L. (2017). Anxiety and Depression in Cancer Survivors. Medical Clinics of North America, 101, 1099-1113. doi: 10.1016/j.mcna.2017.06.005.

Zigmond, A.S., \& Snaith, R.P. (1983). The hospital anxiety and depression scale. Acta Psychiatrica Scandinavica, 67, 361-370. doi: 10.1111/j.16000447. 1983.tb09716. x. 